\title{
Improving participation by Aboriginal children in blood lead screening services in Broken Hill, NSW
}

\author{
Susan L. Thomas ${ }^{\mathrm{A}, \mathrm{C}}$, Frances Boreland ${ }^{\mathrm{B}}$ \\ and David M. Lyle \\ ${ }^{\mathrm{A}}$ NSW Public Health Officer Training Program, \\ NSW Ministry of Health \\ ${ }^{\mathrm{B}}$ Broken Hill University Department of Rural Health, \\ The University of Sydney \\ ${ }^{\mathrm{C}}$ Corresponding author: Email: s.thomas@flinders.edu.au
}

Abstract: Lead poses a health risk to young children with detrimental effects on their intellectual development. Attendance rates for Aboriginal children at routine blood lead screening and at follow-up appointments in Broken Hill, NSW, have declined in recent years. This study sought to identify strategies to improve the participation of Aboriginal children aged 1-4 years in blood lead screening services in Broken Hill. Methods: Attendance rates during the period 2000-2010 were determined using the Broken Hill Lead Management database. From June to August 2011, Aboriginal community members, service providers and public health staff were invited to interviews and focus groups to explore barriers, enablers and suggestions for improving participation. Results: In 2009, 27\% of Aboriginal children aged 1-4 years attended blood lead screening and $29 \%$ of these children with blood lead levels over $15 \mu \mathrm{g} / \mathrm{dL}$ attended follow-up appointments. Barriers to participation in lead screening services included community perceptions, reduced service capacity, socio-economic and interorganisational factors. Enablers included using a culturally acceptable model, linking lead screening with routine health checks and using the finger-prick method of testing. Conclusions: The final report for the study included recommendations to improve participation rates of Aboriginal children including using social marketing, formalising collaboration between health services, supporting disadvantaged families and employing an Aboriginal Health Worker.
Exposure to lead poses a health risk particularly to young children with detrimental effects on their intellectual development. ${ }^{1}$ The mining town of Broken Hill, New South Wales (NSW), was built around one of the world's largest silver-lead-zinc ore deposits and has been mined continuously since 1884. In 1991 a survey of pre-school aged children in Broken Hill found lead was a significant public health issue; a state government-funded Lead Management Program was established in 1994 to reduce blood lead levels in children aged $1-4$ years. ${ }^{2}$ The program which included blood lead screening began as an adequately resourced, stand-alone service until 2001, when it was integrated into existing child health services and its dedicated funding finished at the end of 2006. Services are currently offered by the Broken Hill Child and Family Health Services and Maari Ma Health Aboriginal Corporation (Maari Ma). In 2004, 80\% of Aboriginal children attended screening services. After 2004 attendance rates for Aboriginal children began declining and reached a low of $27 \%$ in 2009 , below that of the general population $(37 \%){ }^{3}$

There is no known threshold defining 'safe' levels of exposure to lead, but the National Health and Medical Research Council currently recommends interventions at a community level when appreciable numbers of children have blood lead levels exceeding $10 \mu \mathrm{g} / \mathrm{dL} .{ }^{1}$ Forty percent of Aboriginal children aged 1-4 years screened in 2010 were above $10 \mu \mathrm{g} / \mathrm{dL} .^{3}$ Blood lead levels $15 \mu \mathrm{g} / \mathrm{dL}$ and above are notifiable to NSW Health. ${ }^{*}$ In 2010, 21\% of Aboriginal children screened had blood lead levels requiring notification. ${ }^{3}$ Aboriginal people continue to experience socio-economic disadvantage which places them at greater risk of exposure to behavioural and environmental health risk factors, ${ }^{4}$ and this should be taken into consideration in the planning and provision of relevant services.

In 2011, we undertook a study to gain a better understanding of the decline in screening rates in Aboriginal children aged 1-4 years and to identify strategies to improve their participation in blood lead screening services in Broken Hill. The study was undertaken on behalf of the Far West Local Health District.

*In December 2011, the mandatory notification level changed to $10 \mu \mathrm{g} / \mathrm{dL}$ or above. 
Table 1. Number and type of participants in interviews and focus groups undertaken in Broken Hill, NSW, 2011

\begin{tabular}{lccc} 
& Interviews & Focus groups & Focus group participants \\
& $n$ & $n$ & $n$ \\
Community members & 15 & 0 & 0 \\
Broken Hill Child and Family Health Services & 1 & 1 & 4 \\
Maari Ma Health Aboriginal Corporation & 2 & 1 & 4 \\
Broken Hill University Department of Rural Health & 0 & 1 & 3 \\
Total & 18 & 3 & 11 \\
\hline
\end{tabular}

\section{Methods}

The study took place in two phases. The first involved reviewing data from the Broken Hill Lead Management Program, set up as part of the original lead program to record children's test results. The second phase used qualitative methods to explore emerging themes. ${ }^{5}$ Semistructured interviews and focus groups with Aboriginal parents and carers of young children, service providers and public health staff were used to gain a better understanding of:

- the perceptions of the health risks of lead for children

- the reason for the downward trend in Aboriginal children's attendance at screening programs

- how these declining attendance rates might be improved.

\section{Broken Hill Lead Management database}

De-identified data from the Broken Hill Lead Management database from 2000 to 2010 were reviewed. Records for Aboriginal children aged 1-4 years of age were extracted. Duplicates and those with missing blood lead values were excluded, leaving a data set of 864 . Attendance rates for annual screening were calculated for children recorded as having attended blood lead screening at least once in a calendar year. Australian Bureau of Statistics Census data for 2001 and 2006 were used to calculate screening rates. ${ }^{6}$ Attendance rates for follow-up visits by children whose blood lead levels were $15 \mu \mathrm{g} / \mathrm{dL}$ and above from 2004 to 2010 were also calculated.

\section{Lead Health Program Testing Schedule}

Attendance at follow-up appointments was measured against the protocol outlined in the Lead Health Program Testing Schedule and Interventions (available on request from Broken Hill Child and Family Health Services). Children were grouped according to whether or not their follow-up visits were in accordance with recommendations in the protocol. Children with a blood lead level between 11 and $20 \mu \mathrm{g} / \mathrm{dL}$ are requested to return at 6 -month intervals for follow-up testing. Children with levels between 21 and $39 \mu \mathrm{g} / \mathrm{dL}$ are requested to return at 3 -month intervals and those with levels $40-49 \mu \mathrm{g} / \mathrm{dL}$ at 1 -month intervals. Case management including education and home assessment to identify the pathway of lead ingestion is offered to all families of children with blood lead levels over $10 \mu \mathrm{g} / \mathrm{dL}$.

\section{Interviews and focus groups}

Participants with a range of relevant experience, skills and knowledge were invited to interviews and focus groups (Table 1). Aboriginal parents or carers of young children were invited to informal interviews at an Aboriginal preschool and an Aboriginal playgroup. Interviews were conducted while participants were involved in the routine functions of the centre (e.g. playing with children, helping with morning tea). Service managers were invited to individual interviews in order to explore planning and management strategies. Two interviews were conducted at their place of work and one was by telephone. Three focus groups were conducted with health professionals to facilitate discussion and the exchange of ideas and to reflect on blood lead screening services for Aboriginal families. Participants included lead screening staff, a health promotion officer, an early childhood health nurse, a practice nurse, research staff and an epidemiologist.

Interviews with community members lasted approximately 10 minutes while other interviews and focus groups were 40-60 minutes. Informed consent was obtained from all participants. Confidentiality and privacy were ensured as contributions used in the report were de-identified. Interviews were sound recorded (with the exception of interviews with community members where written records were taken), transcribed, and analysed manually to identify barriers, enablers and strategies. The study investigators verified the resultant material.

Ethics approval was obtained from the former Greater Western Area Health Service Human Research Ethics Committee (HREC /11/GWAHS/4) and from the Aboriginal Health and Medical Research Council of NSW (AHMRC, 771/11).

\section{Results}

Attendance rates at blood lead screening services for Aboriginal children aged 1-4 years increased steadily from $55 \%$ in 2000 to $80 \%$ in 2004 . From 2005 attendance rates gradually declined and reached a low of $27 \%$ in 2009 . The screening rate began to improve in 2010 , increasing to $39 \%$ (Table 2) 
Table 2. Number and estimated percentage of Aboriginal children aged 1-4 years, screened at least once for blood lead levels in Broken Hill, NSW, 2000-2010

\begin{tabular}{cccc}
\hline Year & $\begin{array}{c}\text { Aboriginal } \\
\text { children screened } \\
\boldsymbol{n}\end{array}$ & $\begin{array}{c}\text { Estimated } \\
\text { Aboriginal population } \\
\boldsymbol{n}\end{array}$ & $\%$ \\
\hline 2000 & 75 & 137 & 55 \\
2001 & 85 & 137 & 62 \\
2002 & 96 & 137 & 70 \\
2003 & 98 & 137 & 72 \\
2004 & 110 & 137 & 80 \\
2005 & 97 & 137 & 71 \\
2006 & 71 & 144 & 49 \\
2007 & 81 & 144 & 56 \\
2008 & 56 & 144 & 39 \\
2009 & 39 & 144 & 27 \\
2010 & 56 & 144 & 39 \\
\hline
\end{tabular}

Sources: Broken Hill Lead Management database; 2001 and 2006 Australian Bureau of Statistics Census data.

Table 3. Number and percentage of Aboriginal children aged $1-4$ years with blood lead levels $15 \mu \mathrm{g} / \mathrm{dL}$ or more who attended follow-up appointments in Broken Hill, NSW, 2004-2010

\begin{tabular}{lccc} 
Year & $\begin{array}{c}\text { Blood lead } \\
\text { level } \geq 15 \mu \mathrm{g} / \mathrm{dL} \\
n\end{array}$ & $\begin{array}{c}\text { Follow-up } \\
\text { attendance } \\
n\end{array}$ & $\begin{array}{c}\text { Percentage } \\
\text { followed-up } \\
\%\end{array}$ \\
\hline 2004 & 33 & 26 & 79 \\
2005 & 22 & 11 & 50 \\
2006 & 20 & 8 & 40 \\
2007 & 19 & 9 & 47 \\
2008 & 12 & 5 & 42 \\
2009 & 7 & 2 & 29 \\
$2010^{*}$ & 12 & 4 & 33 \\
\hline
\end{tabular}

*2010 contains some missing data for follow-up due in 2011 Source: Broken Hill Lead Management database.

Follow-up rates for Aboriginal children aged 1-4 years whose blood lead levels were $15 \mu \mathrm{g} / \mathrm{dL}$ and above have declined from 2004 when $79 \%$ attended follow-up appointments. In 2009, 29\% returned for follow-up and in $2010,33 \%$ returned (Table 3).

The findings from the interviews and focus groups were grouped into common themes to identify why Aboriginal children's attendance at screening programs was declining and how attendance might be improved: barriers, enablers and strategies.

\section{Barriers}

Community members generally agreed that health risks and the importance of screening were not well promoted. Many participants recalled risks related to learning and intellectual development but had forgotten health messages about ways to reduce the risk of lead ingestion. Many referred to the fact that there was no practical or financial help for affected families to act on recommendations by health staff (e.g. fixing cracks in ceilings, planting grass over dirt yards) and that this lack of support was a significant barrier to attending screening services. Some community members commented that there were other more important priorities for many families.

Service providers described barriers related to service capacity and funding for key positions. Most agreed that community perceptions were a significant factor in preventing uptake of health services for Aboriginal children:

\section{People don't see lead as a health issue anymore because we're not telling them it's a health issue. (Focus group)}

There was an Aboriginal Health Worker that worked with our program. That was a fantastic way to identify and communicate the lead problem with the Aboriginal community. Unfortunately that position no longer exists. (Focus group)

There was wide agreement among service providers that socio-economic barriers needed to be acknowledged and were factors contributing to the decline in attendance at screening services. Service providers commented that families felt there was nothing that could be done to help them if their child had elevated blood lead levels:

\section{.....[families with limited resources are] living in rental} houses, landlords are not going to plant lawn, they're not going to clean the ceilings out, they're not going to help them so there is a ...this is the best I can do...I can keep my kids' hands clean, I can keep my house clean, but when you're living in a house and the dust is coming through the roof, the dust storms are coming through the house, how do you do it? (Focus group)

Service providers also discussed gaps in communication between health services, including no formal meetings to share information or discuss issues related to declining attendance rates and strategies. Some service providers and managers were not aware of information available from the Lead Management database. That services did not share case management of Aboriginal children with high lead levels or do joint home visits were raised as issues for Aboriginal families.

\section{Enablers}

Many community members recalled the special lead screening days held at Maari Ma and felt that these encouraged families to come for their children's screening. They also felt that using the finger-prick testing method and assisting with transport to the centre encouraged the community to bring their children for screening. 
Service providers described enabling factors related to service capacity: providing the lead screening service within a model of care that was culturally acceptable to the Aboriginal community and providing verbal information, as opposed to telephone reminders or letters, with face-to-face communication, home visiting, flexible screening times and culturally appropriate resource materials.

One of the best things we did was organise the intake of 11 trainee health workers for the Certificate IV [in Aboriginal and/or Torres Strait Islander Primary Health Care]. So the engagement of people around the community has been far, far greater. And the workforce is very mobile; they're very community based as well. (Focus group)

The first people they see are Aboriginal people, the next line of people they see are Aboriginal people and so, Aboriginal Health in Aboriginal Hands, there's nothing works better. (Service manager)

There was wide agreement among service providers and public health staff that linking lead screening with other services such as immunisation and child development checks was proving to be successful in increasing attendance.

\section{Suggestions for action}

Many community members wanted to see health messages relating to lead promoted in the community. Most spoke fondly of the old lead mascot 'Lead Ted' and would like to see a return of the specific lead screening days held at Maari Ma.

Service providers agreed that more funding, even if not to health directly, would be helpful in re-engaging with the community in a variety of ways including assisting those in financial need. Further expansion of services at Maari Ma was also seen as important, including ongoing or additional training so that staff could provide case management as well as screening services. Some felt that better use of the Lead Management database would help service providers identify and respond to declining attendance rates for screening of lead in Aboriginal children.

Public health staff were in agreement with the other service providers in terms of barriers and enablers to lead screening. They felt it was important to re-engage with the community, perhaps through the Aboriginal Community Working Party in Broken Hill, to increase confidence that help was available for children with high lead levels.

\section{Discussion}

This study shows a steady increase in screening rates for Aboriginal children from 2000 to 2004 despite declining investment in lead awareness and the Lead Management
Program's integration into existing health services. The screening rate for Aboriginal children was high in 2004 $(80 \%)$ after which it declined. Two factors that may explain the high attendance rates at this time were the special days for lead screening that were taking place at Maari Ma and the role of an Aboriginal Health Worker employed by Child and Family Health Services to identify Aboriginal children who were due for a blood lead test and to encourage and assist families to bring those children to the centre. After 2004 dedicated resources ceased and as a consequence both the position of Aboriginal Health Worker and the special lead screening days at Maari Ma ended. Attendance rates began to decline in annual screening and follow-up. The rates of testing and followup were lowest in 2009 when Maari Ma experienced a decline in workforce capacity. The low rates of follow-up are of concern as they indicate that even children with elevated blood lead levels are not engaging with the available services offered through case management, including education, home visiting, soil sampling and further monitoring of blood lead levels. Attendance and follow-up rates for Aboriginal children increased slightly in 2010, since Maari Ma has begun offering finger-prick testing.

Maari Ma, which now screens the majority of Aboriginal children in Broken Hill, identified logistical barriers to the participation by Aboriginal children in lead screening services related to workforce capacity, the physical space currently available and the difficulty of ensuring the correct environment to conduct the test (e.g. room temperature, dust-free). A new facility is being built and Maari Ma has recently supported a cohort of Certificate IV Aboriginal and Torres Strait Islander Primary Health students, which will help to address these barriers. Some Aboriginal families were not comfortable engaging with government services, an important barrier to health screening as it is the government services which currently provide comprehensive case management of children with elevated blood lead levels. Staff at Maari Ma were concerned that some Aboriginal families have felt judged by government health services and feared having their children removed, particularly when a home visit was recommended.

In terms of improving current participation rates, Maari Ma staff described issues related to service capacity such as having the right people in the right positions with the right training, and issues related to their service model such as face-to-face communication, home visiting to follow-up those who did not attend appointments and providing transport to assist families. This approach suggests that using a culturally appropriate model, combined with other strategies aimed at community engagement are likely to be successful in improving blood lead screening rates for Aboriginal children aged $1-4$ years. 
Community members expressed concern over the difficulty or inconvenience for some people to prove their Aboriginal status to access Maari Ma health services. There was also some concern that as the Aboriginal community in Broken Hill is small some patients may have a personal relationship with service providers, which may discourage them from using the service. While access to an Aboriginal Community Controlled Heath Service (ACCHS) is important and provides a culturally appropriate and safe environment for families, it is also important for people to have a choice of services.

Recommendations were developed from the findings and from discussions with stakeholders involved in lead management services in Broken Hill and are included in a report prepared for the Far West Local Health District. These recommendations focus on re-engaging with the Aboriginal community to develop and implement programs to promote lead screening, formalising relationships between government and ACCHSs at both the local and regional level, seeking funding to assist disadvantaged families, linking lead screening with routine health visits and re-instating the dedicated position of an Aboriginal Health Worker.

\section{Conclusion}

The findings of this study are encouraging. While attendance and follow-up rates have declined in recent years, there have been periods of very high attendance rates by Aboriginal children despite reductions in lead program funding. Aboriginal community members have expressed a desire to see lead health promoted again in the community. Interviews and focus groups have confirmed a commitment to lead as an important health issue by staff and managers of child health services in Broken Hill. Using a culturally appropriate model, supporting disadvantaged families and developing collaborative partnerships are needed to increase participation in lead screening services. These findings can be used to inform policy and planning.

\section{Acknowledgments}

The authors would like to thank the community members, service providers and public health staff in Broken Hill for their generous participation in this study. We also thank the Aboriginal Community Working Party and members of the study's Advisory Group for their valuable assistance and advice, and Margie Lesjak, senior epidemiologist, Broken Hill Public Health Unit, Far West Local Health District who assisted by providing data from the Lead Management database. This work was completed while Susan Thomas was an employee of the NSW Public Health Officer Training Program, funded by the NSW Ministry of Health. She undertook this work while based at the University Department of Rural Health, The University of Sydney.

\section{References}

1. National Health and Medical Research Council. Information paper. Blood lead levels for Australians. August 2009. Available at: http://www.nhmrc.gov.au/_files_nhmrc/publications/ attachments/gp2-lead-info-paper.pdf (Cited 10 September 2011).

2. Lyle DM, Phillips AR, Balding WA, Burke H, Stokes D, Corbett S et al. Dealing with lead in Broken Hill - Trends in blood lead levels in young children 1991-2003. Sci Total Environ 2006; 359: 111-9. doi:10.1016/j.scitotenv.2005.04.022

3. Greater Western Area Health Service. Blood lead trends in children aged less than 5 years in Broken Hill 2010. Available at: http://www.gwahs.nsw.gov.au/userfiles/file/BH\%20Lead\% 20Health\%20Annual\%20Report\%202010.pdf (Cited 14 May 2012).

4. Centre for Epidemiology and Research. The health of the people of New South Wales. Summary Report. Report of the Chief Health Officer 2010. Sydney: NSW Department of Health; 2010. Available at: http://www.health.nsw.gov.au/pubs/2010/pdf/ chorep_summary_2010.pdf (Cited 10 September 2011).

5. Carter SM, Ritchie JE, Sainsbury P. Doing good qualitative research in public health: not as easy as it looks. $N S W$ Public Health Bull 2009; 20: 105-11. doi:10.1071/NB09018

6. Australian Bureau of Statistics. 2006 Census Tables, Broken Hill. Available at: http://www.censusdata.abs.gov.au/ (Cited 10 September 2011).

\section{Update on actions to improve lead screening rates in Aboriginal children in Broken Hill}

Participation in lead screening by Aboriginal children in Broken Hill has improved since the study was completed. In 2011, $70 \%$ of Aboriginal children were tested (up from 40\% in 2010). ${ }^{1}$ This improved participation may be attributed to concerted efforts at both local and regional levels. As a first step the findings of the study were widely disseminated to stakeholders (service managers, providers and the Aboriginal Community Working Party). A lead health workshop was held in Broken Hill, and was attended by environmental health and toxicological experts and population health staff from the Far West Local Health District. Strategic planning meetings led by the Local Health District and attended by a range of service managers and providers focused on lead. Lead screening was aligned with the childhood immunisation schedule and reminders were sent to parents. While initial testing of most Aboriginal children is conducted at Maari Ma Health Aboriginal Corporation, there is greater collaboration now with the Broken Hill Child and Family Health Services for case management of children with high lead levels than was reported in the study. These efforts have seen lead screening rates in Aboriginal children return to previously high levels.

1. Far West Local Health District. Blood lead trends in children aged less than 5 years in Broken Hill 2011. Available at: http://www. fwlhn.health.nsw.gov.au/UserFiles/files/FAR\%20WEST\%20Lead\%20Health\%20Data\%20Report\%202011.pdf (Cited 21 November 2012). 